\title{
Tests and analysis of reinforced concrete beams under torsion retrofitted with FRP strips
}

\author{
C. E. Chalioris \\ Department of Civil Engineering, Democritus University of Thrace, \\ Greece
}

\begin{abstract}
The aim of the present study is twofold. First, the results of an experimental investigation on the torsional response of reinforced concrete (RC) beams retrofitted with epoxy-bonded carbon fibre-reinforced-polymer (FRP) strips as external transverse reinforcement are presented. Second, an analytical approach for the estimation of the torsional capacity and the entire behaviour of RC beams retrofitted with FRP fabrics is attempted. The experimental program comprises eight beams with a rectangular cross-section tested under pure torsion. Based on the measured values of the torsional moment at cracking and at ultimate and the behavioural curves of the beams, useful conclusions concerning the effectiveness of the FRP strengthening technique are indicated. Further, in order to describe the entire torsional behaviour of RC beams retrofitted with FRP, a method that employs the combination of two different analytical theories is used. The prediction of the elastic till the first cracking part is achieved using a smeared crack analysis for plain concrete in torsion, whereas for the description of the post-cracking response a modified softened truss model is proposed. The wellknown softened truss model is properly modified to include the influence of the FRP fabrics on the torsional response as external reinforcement. Analytical torsional behaviour curves are compared with experimental ones from the present study and the literature, and first concluding remarks are mentioned.

Keywords: beams, reinforced concrete, fibre-reinforced polymers (FRP), retrofit, model, torsion, tests.
\end{abstract}




\section{Introduction}

Torsion occurs more frequently in modern structures but rarely occurs alone. However, torsion forms one of the basic structural actions besides flexure, shear and axial force. Torsional failure of concrete members is initiated by the tensile stress developed due to a state of pure shear, which arises due to torsion [1]. Epoxy-bonded Fibre-Reinforced Polymers (FRP) materials to the surface of Reinforced Concrete (RC) members are considered as external reinforcement that can bear the developed tensile stresses.

The advanced mechanical properties and the easy-to-apply character of these composite materials inspired the researchers to study their use on strengthening and rehabilitation of deficit concrete elements. A growing number of studies and applications in this area has been carried out for the flexural and shear strengthening of RC subassemblages under monotonic and cyclic deformations [2-4]. Nevertheless, the conducted research on the torsional upgrading of RC beams using FRP materials is quite limited and has preliminary and exploratory character so far. Earlier investigations indicated that FRP materials caused a significant increase on the torsional capacity of the tested beams [5-7]. Torsion of plain, steel reinforced and fibre reinforced concrete beams has extensively been studied by several experimental and analytical researches [8-11].

The present study deals with the upgrading of torsional resistance of RC beams using FRP fabrics, which is still an open field of study. The recent increase interest for the use of these materials, the catastrophic character of the torsional failure and the lack of relative studies are the main motives behind this effort.

The objective of this work has two parts; an experimental and an analytical one. The experimental program consists of 8 specimens and aims to evaluate the effectiveness of the use of epoxy-bonded carbon FRP strips as external transverse reinforcement to RC beams subjected to pure torsion. The analytical part of the study employs a method that has already been used for the prediction of the entire torsional response of RC beams $[12,13]$. This model derives from the combination of two well-known theories $[1,14]$ and it is properly modified herein, in order to include the influence of the FRP materials on the torsional behaviour.

\section{Experimental program}

The experimental program comprises 8 beams of rectangular cross-section sorted in two groups ( $\mathrm{Ra}$ and $\mathrm{Rb}$ ) and tested under pure torsion action. The crosssection dimensions of the beams of group Ra was $100 / 200 \mathrm{~mm}$, whereas the beams of group $\mathrm{Rb}$ had cross-section dimensions 150/300 mm. Each group comprises four specimens. Two of them were strengthened using epoxy-bonded carbon FRP strips that wrapped around the rectangular cross-section of the beams as external transverse reinforcement. The longitudinal reinforcement of all 
the tested specimens was the same; four deformed bars of diameter $8 \mathrm{~mm}(4 \varnothing 8)$ at the corners of the rectangular cross-section. The transverse reinforcement of the beams varies (none, steel stirrups or/and FRP strips) as shown in Table 1. Reinforcement arrangement of all the tested beams is also presented in Table 1. The concrete compressive and tensile strength values were measured from supplementary compression and splitting tests, respectively, and equal to 27.5 $\mathrm{MPa}$ and $2.8 \mathrm{MPa}$ for the beams of group $\mathrm{Ra}$ and $28.8 \mathrm{MPa}$ and $2.9 \mathrm{MPa}$ for the beams of group Rb. Steel yield strength was $560 \mathrm{MPa}$ for the $\varnothing 8$ deformed longitudinal steel bars and $350 \mathrm{MPa}$ for the $\varnothing 5.5$ mild steel stirrups. Unidirectional carbon FRP fabrics with thickness $t_{\mathrm{f}}=0.11 \mathrm{~mm}$ per ply were used as external transverse reinforcement (SikaWrap-200C). The fibre direction oriented perpendicular to the longitudinal axis of the beam. According to the FRP supplier data, the elastic modulus, the ultimate tensile strength and the elongation at failure of the fibres were $230 \mathrm{GPa}, 3900 \mathrm{MPa}$ and $1.5 \% \mathrm{~mm} / \mathrm{mm}$, respectively. A two-component rubber-toughened cold-curing-construction epoxy adhesive with density $1310 \mathrm{~kg} / \mathrm{m}^{3}$, elastic modulus $3800 \mathrm{MPa}$ and tensile strength $30 \mathrm{MPa}$ was used for bonding the FRP strips to concrete (Sikadur 330).

Table 1: $\quad$ Reinforcement and concrete strength of tested beams.

\begin{tabular}{|c|c|c|c|c|c|c|c|c|c|}
\hline \multirow{2}{*}{$\begin{array}{c}\text { Beam code } \\
\text { name }\end{array}$} & \multirow{2}{*}{$\begin{array}{l}\text { Steel } \\
\text { bars } \\
(\mathrm{mm})\end{array}$} & \multirow{2}{*}{$\begin{array}{c}\text { Steel } \\
\text { stirrups } \\
(\mathrm{mm})\end{array}$} & \multicolumn{4}{|c|}{ FRP strips } & \multirow{2}{*}{$\begin{array}{l}\rho_{s \ell}^{n} \\
(\%)\end{array}$} & \multirow{2}{*}{$\begin{array}{l}\rho_{s t}^{n} \\
(\%)\end{array}$} & \multirow{2}{*}{$\begin{array}{l}\rho_{f t}^{n} \\
(\%)\end{array}$} \\
\hline & & & $\mathrm{n}_{\mathrm{f}}$ & $\begin{array}{c}\mathrm{W}_{\mathrm{f}} \\
(\mathrm{mm})\end{array}$ & $\begin{array}{c}\mathrm{s}_{\mathrm{f}} \\
(\mathrm{mm})\end{array}$ & $\begin{array}{c}\mathrm{A}_{\mathrm{f}} / \mathrm{s}_{\mathrm{f}} \\
(\mathrm{mm})\end{array}$ & & & \\
\hline $\mathrm{Ra}-\mathrm{c}$ & $4 \varnothing 8$ & - & - & - & - & - & 1.01 & - & - \\
\hline Ra-Fs150(2) & $4 \varnothing 8$ & - & 2 & 150 & 300 & 0.110 & 1.01 & - & 0.33 \\
\hline $\mathrm{Ra}-\mathrm{S}$ & $4 \varnothing 8$ & $\varnothing 5.5 / 130$ & - & - & - & - & 1.01 & 0.38 & - \\
\hline Ra-SFs150(2) & $4 \varnothing 8$ & $\varnothing 5.5 / 130$ & 2 & 150 & 300 & 0.110 & 1.01 & 0.38 & 0.33 \\
\hline $\mathrm{Rb}-\mathrm{c}$ & $4 \varnothing 8$ & - & - & - & - & - & 0.45 & - & - \\
\hline Rb-Fs200(1) & $4 \varnothing 8$ & - & 1 & 200 & 400 & 0.055 & 0.45 & - & 0.11 \\
\hline $\mathrm{Rb}-\mathrm{S}$ & $4 \varnothing 8$ & $\varnothing 5.5 / 100$ & - & - & - & - & 0.45 & 0.38 & - \\
\hline Rb-SFs200(1) & $4 \varnothing 8$ & $\varnothing 5.5 / 100$ & 1 & 200 & 400 & 0.055 & 0.45 & 0.38 & 0.11 \\
\hline
\end{tabular}

All tested specimens had common total length equal to $1.60 \mathrm{~m}$ and were tested monotonically under pure torsion. Details about the experimental apparatus and the test procedure can be found in references 7 and 13. The values of torque moment at cracking and ultimate torque moment, as measured from the tests, are presented in Table 2. Further, the entire torsional behaviour of the beams is also presented in Figure 1 in terms of torsional moment versus angle of twist per unit length experimental curves. 


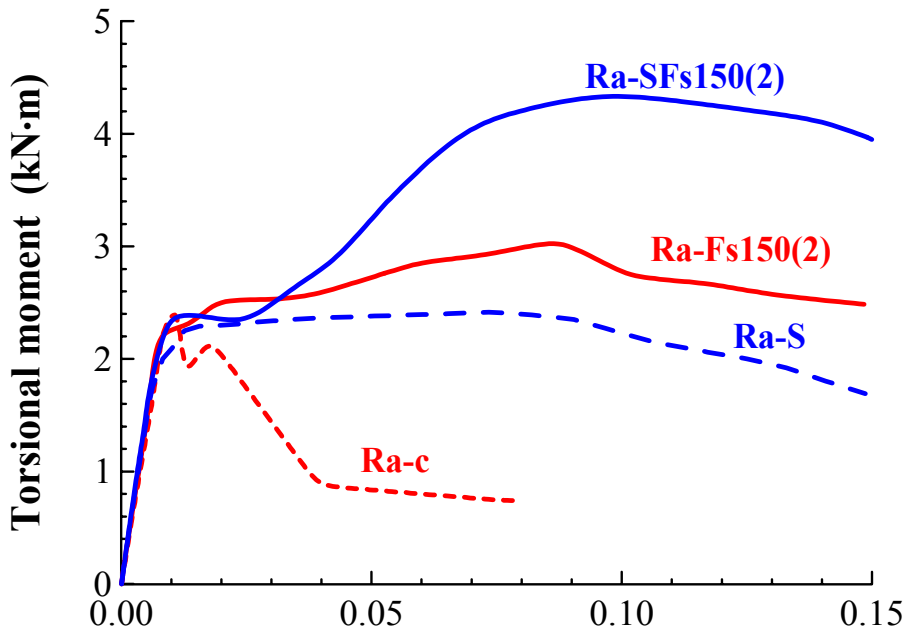

Angle of twist per length ( $\mathrm{rad} / \mathrm{m})$

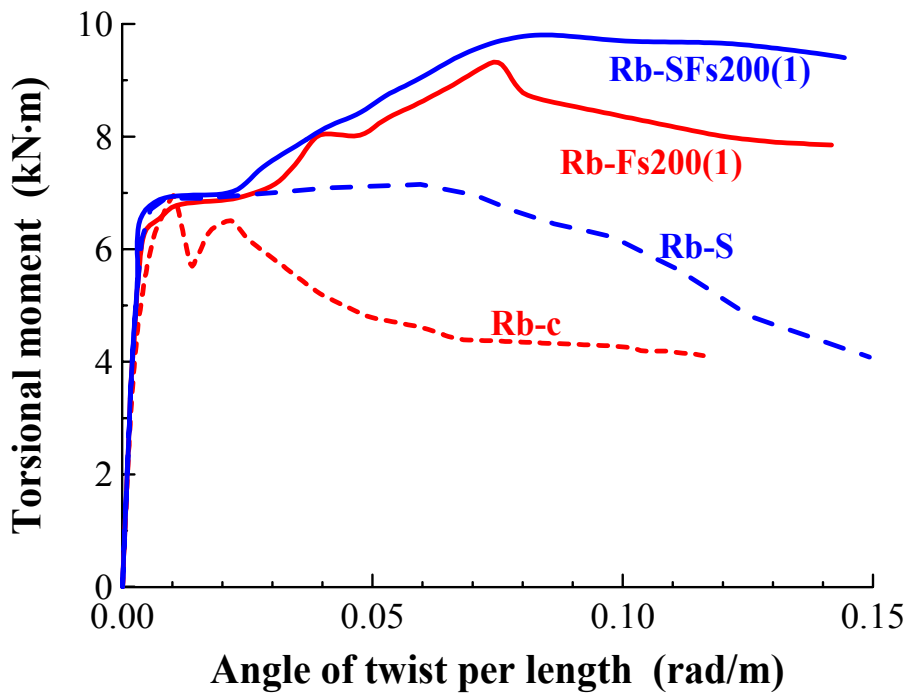

Figure 1: Experimental curves of the tested beams.

\section{Behavioural model and comparisons with test results}

The prediction of the entire torsional behaviour of RC beams strengthened with FRP strips is achieved using a combined approach that has already been proposed for RC beams $[12,13]$. In the present study this method is extended to include the influence of FRP fabrics. The method employs the combination of two different analytical models, since the torsional response of RC members consists of a pre-cracking and a post-cracking part and justifies this 
simulation [13]. The elastic till the first cracking part is described by a smeared crack analysis for plain concrete in torsion [1] and the post-cracking part is described by a softened truss model [14].

It is justified that for the elastic till the first cracking region the percentage of reinforcement has a minor effect on the torsional response and RC elements behave, more or less, as plain concrete members. Therefore, the analytical smeared crack model for plain concrete in torsion proposed by Karayannis [1] is applicable to RC beams for the prediction of the first elastic part till the developing of concrete cracking. The model is based on an analytical technique that employs constitutive relations expressed in terms of normal stress and crack width, for the behaviour of the crack process zones. Detailed derivation of the equations and the solution technique of this theory can be found in reference 1 .

For the calculation of the torsional behaviour of a RC beam strengthened with FRP strips in the post-cracking region the basic equations and considerations of the softened truss model [14] are adopted and properly modified. This method relies on solving three equilibrium and three compatibility equations along with the constitutive laws of an element taken from a member subjected to pure torsion. The equations of equilibrium and compatibility are based on the assumption that the material is continuous. Especially for the concrete in compression, it is considered that concrete struts strength is greatly reduced by the diagonal cracking caused by tension in the perpendicular direction (concrete softening). The influence of the epoxy-bonded FRP fabrics as external reinforcement is implemented as an additional component that contributes to the torsional resistance along with the steel reinforcement.

Particularly, considering the state of stress in a finite concrete element of the cracked beam, which is assumed to lie in the plane of the shear flow, it is subjected to a set of stresses in the plane represented by Mohr's circle [14]. Thus, from the stresses equilibrium the following relationships that include the influence of FRP reinforcement are deduced:

$$
\begin{gathered}
\sigma_{\ell}=\sigma_{d} \cos ^{2} \alpha+\sigma_{r} \sin ^{2} \alpha+\rho_{s \ell} f_{s \ell}+\rho_{f \ell} f_{f \ell} \\
\sigma_{t}=\sigma_{d} \sin ^{2} \alpha+\sigma_{r} \cos ^{2} \alpha+\rho_{s t} f_{s t}+\rho_{f t} f_{f t} \\
\tau_{\ell t}=\left(-\sigma_{d}+\sigma_{r}\right) \sin \alpha \cos \alpha
\end{gathered}
$$

where $\sigma_{\ell}$ and $\sigma_{t}$ are the normal stresses of the element in longitudinal and transverse direction, respectively; $\sigma_{d}$ and $\sigma_{r}$ are the principal compressive and tensile stresses, respectively; $\alpha$ is the inclination angle of the diagonal compression struts; $\tau_{\ell t}$ is the shear stress; $\rho_{s \ell}$ and $\rho_{s t}$ are the longitudinal and transverse steel reinforcement ratio, respectively; $\rho_{f \ell}$ and $\rho_{f t}$ are the ratio of the FRP fabrics in longitudinal and transverse direction, respectively; $f_{s \ell}, f_{s t}$, $f_{f \ell}$ and $f_{f t}$ are the stresses of steel and FRP reinforcement in longitudinal and transverse direction. 
It is noted that the above mentioned ratios are not the normalised reinforcement ratios presented in Table 1, but they are calculated by the following expressions:

$\rho_{s \ell}=\frac{A_{s \ell}}{p_{o} t_{d}}$ for the steel bars and $\rho_{s t}=\frac{A_{s t} p_{s t}}{p_{o} t_{d} s}$ for the stirrups, $\rho_{f \ell}=\frac{A_{f \ell}}{p_{o} t_{d}}=\frac{\left(n_{f \ell} \cdot t_{f \ell}\right) p_{f \ell}}{p_{o} t_{d}}$ and $\rho_{f t}=\frac{A_{f t} p_{f t}}{p_{o} t_{d} s_{f}}=\frac{\left(n_{f t} \cdot t_{f t}\right) w_{f} p_{f t}}{p_{o} t_{d} s_{f}}$ for the FRP fabrics in longitudinal and transverse direction, respectively, where $p_{o}$ is the perimeter of the centreline of the shear flow; $t_{d}$ is the effective thickness of the compression zone in the diagonal compression struts; $A_{s \ell}$ is the total area of steel longitudinal bars; $A_{s t}$ is the area of one steel stirrup; $p_{s t}$ is the perimeter of the steel stirrup; $s$ is the spacing of steel stirrups; $n_{f \ell}, n_{f t}$ and $t_{f \ell}, t_{f t}$ are the numbers of plies and the thicknesses of one FRP ply of the epoxy-bonded FRP fabrics in longitudinal and transverse direction, respectively; $p_{f \ell}, p_{f t}$ are the perimeters of the strengthened beam cross-section using FRP fabrics in longitudinal and transverse direction, respectively; $w_{f}$ is the width of the FRP strips; $s_{f}$ is the length along the beam over that FRP area is distributed, which is equal to the spacing between the centroid line of the FRP strips; $A_{f \ell}, A_{f t}$ are the FRP fabrics area in longitudinal and transverse direction, respectively.

Further, the developed tensile stress of the FRP fabrics is calculated by the strain of the fibres, $\varepsilon_{f}$, using the following expression: $f_{f}=E_{f} \varepsilon_{f} \leq f_{f u}$ and $\varepsilon_{f} \leq \varepsilon_{f u}$; where $E_{f}, f_{f u}$ and $\varepsilon_{f u}$ are the elastic modulus, the ultimate tensile strength and the elongation at failure (ultimate strain) of the fibres, respectively.

The shear flow derived from the Bredt equation has the form:

$$
\tau_{\ell t}=\frac{T}{2 A_{o} t_{d}} \text { and therefore } T=2 A_{o} t_{d}\left(-\sigma_{d}+\sigma_{r}\right) \sin \alpha \cos \alpha
$$

where $T$ is the torsional moment; $A_{o}$ is the area enclosed by the centreline of the shear flow.

The compatibility equations relate the shear distortion in the wall, $\gamma_{\ell t}$, to the strains of the concrete and reinforcements:

$$
\begin{gathered}
\varepsilon_{\ell}=\varepsilon_{d} \cos ^{2} \alpha+\varepsilon_{r} \sin ^{2} \alpha \\
\varepsilon_{t}=\varepsilon_{d} \sin ^{2} \alpha+\varepsilon_{r} \cos ^{2} \alpha \\
\gamma_{\ell t}=\left(-\varepsilon_{d}+\varepsilon_{r}\right) \sin 2 \alpha \\
\varepsilon_{\ell}+\varepsilon_{t}=\varepsilon_{d}+\varepsilon_{r}
\end{gathered}
$$


The inclination angle of the diagonal compression struts can be calculated by:

$$
\tan \alpha=\sqrt{\frac{\varepsilon_{\ell}-\varepsilon_{d}}{\varepsilon_{t}-\varepsilon_{d}}}
$$

The angle of twist per unit length, $\vartheta$, is related with the shear distortion:

$$
\vartheta=\frac{p_{o}}{2 A_{o}} \gamma_{\ell t}
$$

Especially for the concrete in compression, it is taking into account the fact that concrete struts strength is reduced by the diagonal cracking caused by tension in the perpendicular direction (concrete softening) and appropriate constitutive laws with softening effect have been formulated [13, 14].

Analyses for the prediction of the torsional behaviour of the 8 tested beams and 5 more beams from the literature [5] using the proposed combined approach were performed. Analytical values of the torsional moment at cracking and the ultimate torsional moment are presented and compared with the measured ones in Table 2. Furthermore, full analytical torque curves for the behaviour of 4 beams are compared with the experimental ones in Figures 2 and 3.

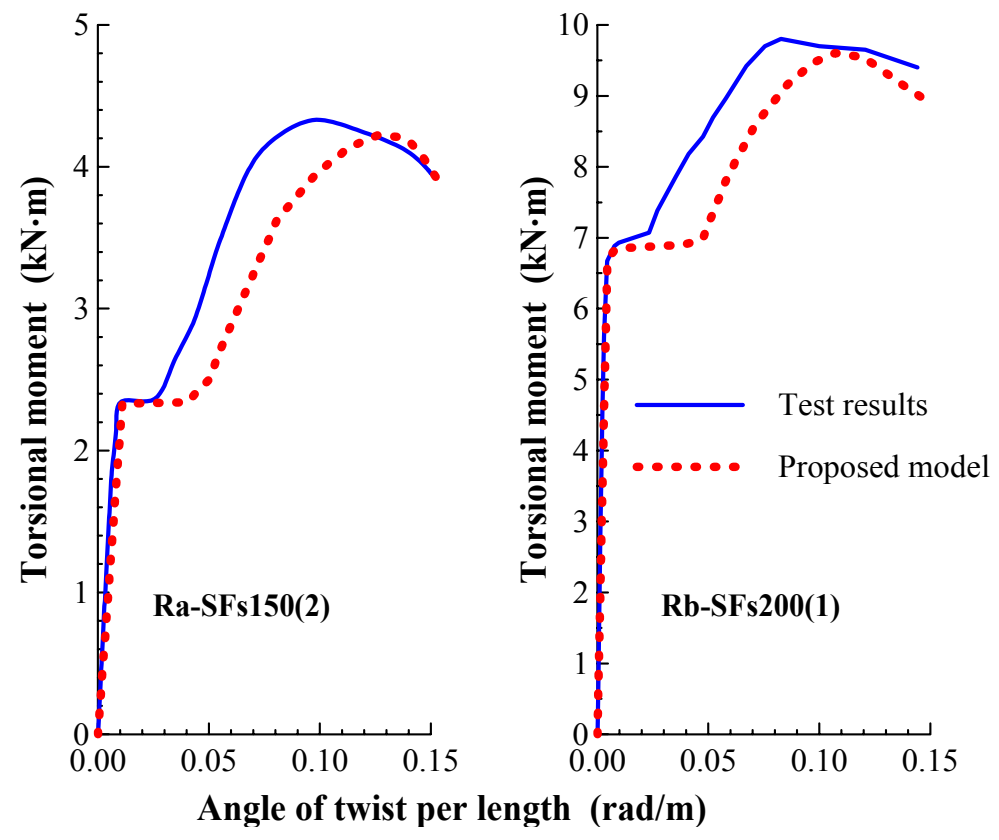

Figure 2: Comparisons between experimental and calculated curves. 

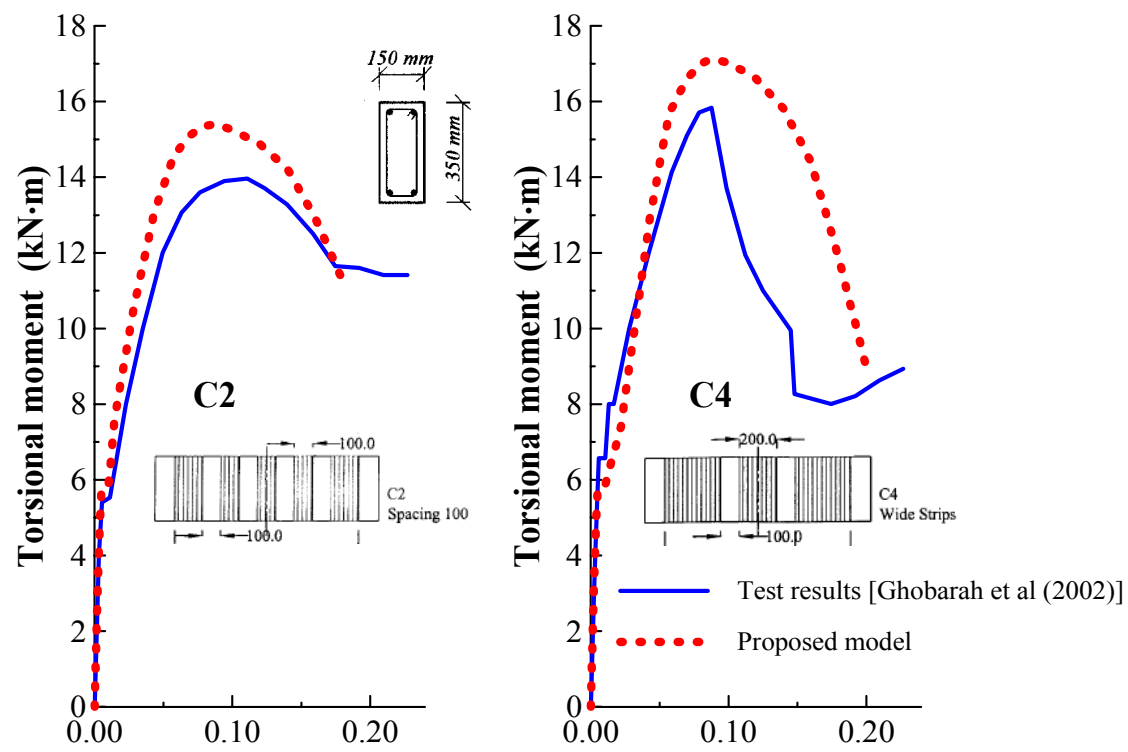

Angle of twist per length ( $\mathrm{rad} / \mathrm{m})$

Figure 3: Comparisons between experimental [5] and calculated curves.

Table 2: $\quad$ Test results and analytical predictions of the tested beams.

\begin{tabular}{|c|c|c|c|c|c|c|}
\hline \multirow{2}{*}{$\begin{array}{l}\text { Beam code } \\
\text { name }\end{array}$} & \multicolumn{3}{|c|}{$\begin{array}{l}\text { Cracking torsional moment } \\
(\mathrm{kN} \cdot \mathrm{m})\end{array}$} & \multicolumn{3}{|c|}{$\begin{array}{l}\text { Ultimate torsional moment } \\
\qquad(\mathrm{kN} \cdot \mathrm{m})\end{array}$} \\
\hline & exp. & calc. & $\frac{\text { exp. }}{\text { calc. }}$ & exp. & calc. & $\frac{\text { exp. }}{\text { calc. }}$ \\
\hline \multicolumn{7}{|c|}{ Present experimental study \& Chalioris [7] } \\
\hline Ra-c & 2.39 & 2.33 & 0.975 & * & - & - \\
\hline Ra-Fs150(2) & 2.22 & 2.33 & 1.050 & 3.02 & 2.75 & 0.911 \\
\hline Ra-S & 2.25 & 2.33 & 1.036 & 2.41 & 2.31 & 0.959 \\
\hline Ra-SFs150(2) & 2.35 & 2.33 & 0.991 & 4.33 & 4.22 & 0.975 \\
\hline $\mathrm{Rb}-\mathrm{c}$ & 6.95 & 6.85 & 0.985 & * & - & - \\
\hline Rb-Fs200(1) & 6.73 & 6.85 & 1.018 & 9.32 & 8.72 & 0.936 \\
\hline $\mathrm{Rb}-\mathrm{S}$ & 6.90 & 6.85 & 0.993 & 7.15 & 6.90 & 0.965 \\
\hline Rb-SFs200(1) & 6.93 & 6.85 & 0.988 & 9.80 & 9.60 & 0.980 \\
\hline \multicolumn{7}{|c|}{ Ghobarah et al [5] } \\
\hline $\mathrm{N} 2$ & 5.00 & 5.75 & 1.150 & 11.02 & 12.11 & 1.099 \\
\hline $\mathrm{C} 2$ & 5.53 & 5.75 & 1.039 & 13.96 & 15.41 & 1.104 \\
\hline $\mathrm{C} 4$ & 6.57 & 5.75 & 0.875 & 15.83 & 17.12 & 1.081 \\
\hline $\mathrm{C} 5$ & 5.87 & 5.75 & 0.979 & 13.42 & 15.08 & 1.124 \\
\hline $\mathrm{G} 2$ & 6.29 & 5.75 & 0.914 & 13.15 & 14.52 & 1.104 \\
\hline
\end{tabular}

*:post-cracking behaviour of the beam did not exhibit increased torsional strength. 


\section{Concluding remarks}

Retrofitting with epoxy-bonded FRP strips is a feasible strengthening technique for existing under-reinforced beams subjected to torsion. Strengthened beams exhibited better overall torsional performance than the non-strengthened control specimens. Failure of wrapped beams with FRP strips was partially delayed in respect to the failure of the control specimens and fibres initially prevented cracking. However, torsional diagonal cracks eventually appeared and widened in the unwrapped concrete of the beams. Two distinct regions are observed in a typical experimental curve of a RC beam with FRP strips. The different character of the response in these regions reveals the different nature of the load resisting mechanism in each part. For the prediction of the entire torsional behaviour of RC beams strengthened with FRP strips a combined method is adopted that employs a smeared crack analysis for the elastic till the first cracking response and a softened truss model that has been extended to include the influence of the FRP fabrics for the post-cracking response. Comparisons between analytical and experimental torque curves showed promising results.

\section{References}

[1] Karayannis, C.G., Smeared Crack Analysis for Plain Concrete in Torsion, Structural Engineering, ASCE, 126(6), pp. 638-645, 2000.

[2] Karayannis, C.G. \& Sirkelis, G.M., Effectiveness of RC Beam-column Connections Strengthening using carbon-FRP Jackets, Proc. of the 12th European Conference on Earthquake Engineering, London, UK, PR 549, 2002.

[3] Tsonos, A. \& Papanikolaou, K., Post-Earthquake Repair and Strengthening of RC Beam-column Connections (Theoretical and Experimental Investigation), Bulletin of the New Zealand National Society for Earthquake Engineering, 36(2), pp. 73-93, 2003.

[4] Chalioris, C.E., Shear Performance of RC Beams using FRP Sheets covering Part of the Shear Span. Proc. of the 1st International Conference on Concrete Repair, St-Malo, Brittany, France, Vol. 2, pp. 809-816, 2003.

[5] Ghobarah, A., Ghorbel, M.N. \& Chidiac, S.E., Upgrading Torsional Resistance of Reinforced Concrete Beams using Fiber-Reinforced Polymer, Composites for Construction, ASCE, 6(4), pp. 257-263, 2002.

[6] Salom, P.R., Gergely, J.M. \& Young, D.T., Torsional Strengthening of Spandrel Beams with Fiber-Reinforced Polymer Laminates, Composites for Construction, ASCE, 8(2), pp. 157-162, 2004.

[7] Chalioris, C.E. Torsional Strengthening of Rectangular and Flanged Beams using Carbon Fibre-Reinforced-Polymers - Experimental Study, Construction and Building Materials, available on-line from 16 Nov. 2006 (to appear in 2007).

[8] Karayannis, C.G. \& Chalioris, C.E., Experimental Validation of Smeared Analysis for Plain Concrete in Torsion, Structural Engineering, ASCE, 126(6), pp. 646-653, 2000. 
[9] Karayannis, C.G., Nonlinear Analysis and Tests of Steel-fiber Concrete Beams in Torsion, Structural Engineering and Mechanics, 9(4), pp. 323338, 2000.

[10] Karayannis, C.G. \& Chalioris, C.E., Strength of Prestressed Concrete Beams in Torsion, Structural Engineering and Mechanics, 10(2), 165$180,2000$.

[11] Chalioris, C.E., Cracking and Ultimate Torque Capacity of Reinforced Concrete Beams, Proc. of the Int. Symposia Celebrating Concrete: People and Practice, University of Dundee, Scotland, UK, Vol. Role of Concrete Bridges in Sustainable Development, pp. 109-118, 2003.

[12] Chalioris, C.E., Behaviour Model and Experimental Study for the Torsion of Reinforced Concrete Members, Proc. of the 3rd Int. Conference: High Performance Structures and Materials, Ostend, Belgium, Wessex Institute of Technology Transactions on The Built Environment, Vol. 85, pp. 459468, 2006.

[13] Chalioris, C.E. Experimental Study of the Torsion of Reinforced Concrete Members, Structural Engineering and Mechanics, 23(6), pp. 713-737, 2006.

[14] Hsu, T.C., Toward a Unified Nomenclature for Reinforced-Concrete Theory, Structural Engineering, ASCE, 122(3), pp. 275-283, 1996. 